\title{
THE IMPACT OF CSR PERCEPTIONS ON WORKERS' INNOVATIVE BEHAVIOUR: EXPLORING THE SOCIAL EXCHANGE PROCESS
}

\author{
Gaudêncio, Pedro \\ Faculdade de Economia da Universidade de Coimbra \\ Instituto Politécnico de Leiria - Centro de Investigação em Gestão para a Sustentabilidade \\ Pedro.gaudencio@gmail.com \\ Coelho, Arnaldo \\ Faculdade de Economia da Universidade de Coimbra \\ Coelho@feuc.pt \\ Ribeiro, Neuza \\ Instituto Politécnico de Leiria - Centro de Investigação em Gestão para a Sustentabilidade \\ Neuza.ribeiro@ipleiria.pt
}

Reference to this paper should be made as follows: Gaudêncio, P., Coelho, A. and Ribeiro, N. (2019) 'Impact of CSR perceptions on workers' innovative behaviour: exploring the social exchange process and the role of perceived external prestige', World Review of Entrepreneurship, Management and Sustainable Development, Vol. 15, Nos. $1 / 2$, pp.151-173. 


\title{
THE IMPACT OF CSR PERCEPTIONS ON WORKERS' INNOVATIVE BEHAVIOUR: EXPLORING THE SOCIAL EXCHANGE PROCESS AND THE ROLE OF PERCEIVED EXTERNAL PRESTIGE
}

\begin{abstract}
The study aims to show how organisational Corporate Social Responsibility (CSR) can influence workers' attitudes, especially in terms of Innovative Behaviour (IB). A second aim is to explore the social exchange process that may underlie this relationship, by examining the mediating role of Organisational Trust (OT), Affective Commitment (AC) and Happiness (HAP) and the moderation role of Perceived External Prestige (PEP). The authors employ structural equation modelling based on survey data obtained from 315 Portuguese individuals. The findings show that perceptions of CSR predict IB through a social exchange process which involves the mediating role of OT, AC and HAP and the moderating process of PEP. They suggest that managers should implement CSR practices because these can contribute towards fostering IB, but also invest in communication and in the process of upgrading corporate image. This study enriches the existing knowledge about social exchange relationships in organisational contexts, and responds to the need to understand underlying mechanisms linking CSR with workers' organisational outcomes, by analysing CSR practices from a holistic stakeholder perspective.
\end{abstract}

Keywords: Corporate Social Responsibility, affective commitment, happiness, perceived external prestige, social exchange, trust 


\section{Introduction}

In business organisations, the importance attributed to issues of ethics and social responsibility has been increasing. The pressures to consider the social and environmental impact of business operations have been growing steadily over the past four decades (Branco \& Delgado, 2011). Corporate Social responsibility (CSR) is an increasingly important topic for organisations (Glavas, 2016). Numerous conceptual articles have been published in major newspapers and trade magazines and now CSR is one of the most prominent concepts in the literature (Turker, 2009b).

Scholars have studied firms' social concerns for many decades; however, it is only recently that interest in CSR has become more widespread (Aguinis \& Glavas, 2012). At an academic level, a growing number of researchers have studied the relationships between CSR and several strategic areas of business such as: financial performance, the influence on consumers, the attraction for investors, and the impact on government relations. Corporate marketing scholars have examined how CSR initiatives help firms develop positive ethical identities and/or relationships with key stakeholders (Hansen et al., 2011).

Issues related to ethics and CSR are still today understood by most managers as purely voluntary and are not globally integrated within a systematic management process in organisations. The topic remained a low priority for most business managers and owners (Branco \& Delgado, 2011). Do companies need to change this policy? The answer to this question seems to be positive. In the review by Aguinis and Glavas (2012) about what we know about CRS, systematic positive relationships were found with firm reputation, consumer evaluation, customer choice, customer loyalty, moral capital, competitive advantage, attractiveness to investors, operational efficiencies, product quality, perceived quality of management, employers' positive attitudes, and financial performance, among others. However, more research is needed to understand how CSR influences employees (Glavas, 2016)

Scholars have argued that stakeholders' perceptions, attitudes and behaviours act as a mediating process in the relationship between an organisation's societal and financial performance (Roeck \& Delobbe, 2012). Inside organisations, workers are one of the main stakeholder groups. They possess, to a greater or lesser extent, three characteristics which validate their role, namely: legitimacy, urgency, and power (Rodrigo \& Arenas, 2008) and they can contribute highly to organisational performance or failure. Because of this, a strategic alignment between the goals of business and workers goals is desirable. Assuming that an organisation's CSR practices have the power to influence workers' behaviour, managers need to understand employees' responses, so it is important to better understand the underlying mechanisms between CSR practices and those responses.

Because enterprises are facing pressure to innovate and improve the efficiency and effectiveness of their business (Wenhua, 2011), and although developing the Innovative Behaviour (IB) of employees is considered to contribute to improving organisational efficiency and effectiveness, very little is known about IB (Xerri, 2013). Hence, it is necessary to explore the issue of why and how the more committed and satisfied worker 
becomes the more innovative one. This implies an investigation of the conditions which underpin such trust within the organisation on the part of the worker.

Such exploration is pertinent since it is known that the innovative behaviour of individuals represents the foundation of any high-performance organisation (Carmelli et al., 2006), contributes to maximise organisational efficiency and effectiveness (Xerri, 2013), and is essential to the development of organisational innovation (Montani et al., 2017). However, while there is a growing body of literature about IB and its importance in the workplace (Xerri, 2013), the link between CSR and IB is largely unexplored and many questions are still to be answered. In this respect, Glavas (2016) poses the question of: "Why, how, and when does CSR lead to the unleashing of creative potential?" Only a few studies have examined the organisational factors required to develop an environment that fosters IB (Xerri, 2013) and little research addresses the issue of how CSR affects employee creativity (Brammer et al., 2015).

CSR initiatives can reflect a positive organisational image that subsequently enhances employees' pride and willingness to be associated with the organisation as a reputable entity (Roeck \& Delobbe, 2012); moreover, firms with a good social responsibility reputation are also likely to generate increased motivation, morale, AC and loyalty among current employees (Branco \& Rodrigues, 2006). However, according to Kim et al. (2010), the role of reflected evaluation ('construed image' or 'perceived external prestige' [PEP]) has not been addressed in CSR studies and it would be helpful to consider whether employees identify primarily through self-evaluation of CSR initiatives or through reflected evaluation of them. Therefore, in this study we explore the role of PEP as a moderator on the influence of CSR on workers' behaviour.

The objective of this study is, therefore, to determine the potential influence of the presence of CSR practices in the workplace, on workers' attitudes, particularly in respect of IB. The study intends to evaluate the importance attached by employees to issues of CSR, to determine whether the CSR practices are influential upon workers' IB, and to identify which types of social exchange can act as mediators and moderators in this link. Specifically, we consider Organisational Trust (OT), Affective Commitment (AC), and Happiness (HAP). We also analyse the data to establish whether the impact of CSR practices on employees is conditioned by their PEP; that is to say, whether CSR only contributes to IB when employees perceive that companies have a good image.

The investigation uses cross-sectional data obtained from a sample of private sector workers. Data collection is based on a structured questionnaire, and structural equations modelling is employed to test the proposed model. A multi-group analysis is performed to test the effects of PEP.

\section{Theoretical Framework}

CSR is related to complex issues such as environmental protection, human resources management, health and safety at work, relations with local communities, suppliers and consumers (Branco \& Rodrigues, 2006). CSR is also the concept most widely used to address relationships between business and society relations (Branco \& Rodrigues, 2006). 
The growing body of literature in the field provides various definitions of CSR (Turker, 2009b). Carroll (1979) defined social responsibility through a model with four components: economic, legal, ethical, and discretionary. To meet their obligation in regard of each of these four components, companies must be productive and profitable, by respecting not only the legal and regulatory requirements, but also unwritten codes, standards and societal values, and must go beyond that by actively contributing towards solving social problems.

Carroll and Shabana (2010) observe that the idea that business enterprises have some responsibility to society beyond that of making profits for the shareholders has been around for centuries, and they provide an excellent review of the historical background to the development of the business case for CSR. At the same time, however, it is argued byBranco and Rodrigues (2006) that firms engage in CSR because they consider that some kind of competitive advantage accrues to them.

It is pertinent for this study to consider the European Commission's (2011) definition of CSR, which is "the responsibility of enterprises for their impacts on society". In this connection, respect for applicable legislation, and for collective agreements between social partners are pre-requisites if that responsibility is to be met. Further, to fully meet their CSR, enterprises should have a process in place to integrate social, environmental, ethical, human rights, and consumer concerns into their business operations and core strategy in close collaboration with their stakeholders.

Among the research studies that have focused on the impact of CSR activities on internal stakeholders, namely employees, there are various efforts that explain these relationships and help us to better understand how CSR can affect worker behaviour. The review by Aguinis and Glavas (2012) that focuses on work attitudes demonstrates that working for socially-responsible companies leads to increased organisational identification, retention, organisational citizenship behaviour, commitment, in-role performance, creative involvement, and also improved employee relations. Nevertheless, Roeck and Delobbe (2012) argue that studies explaining the underlying mechanisms that drive favourable responses to CSR remain largely unexplored. Workers' psychological responses to CSR still need to be investigated, as also do the reasons explaining why and how they happen.

\section{A social exchange approach}

Scholars in organisational behaviour have suggested that a better understanding of the real impact of CSR activities on workers' attitudes can be gained by examining the mediating mechanisms involved (Hansen et al., 2011), and this requires a focus on the nature of the relationships that workers establish with organisations.

In this respect, it is noted that employees are consistently involved in exchange relationships with their organisations (Montani et al., 2017), and hence, Social Exchange Theory (SET) is useful as a model for analysis. Social exchange involves a series of interactions that, over a period of time, generate obligations and liberties between 
workplace social network members (Xerri, 2013). The theory of social exchange (SET) assumes that individuals' social interactions are driven by rational self-interest, and that individuals will only enter and remain in exchange relationships as long as the costs in such relationships do not outweigh their benefits (Wong et al., 2003) but they tend to be mutually dependent and contingent upon the actions of each entity. This exchange is characterised by co-operation and reciprocity - that is when one part provides a benefit to another party, the act generates an obligation on the part of the latter to reciprocate at some point in the future.

In organisations social exchanges are particularly important because they can be decisive in respect of organisational and individual performance. They can be used to explain the link between employee perceptions of workplace aspects and their subsequent behaviour. Researchers have shown that the quality of these relationships is highly influential on employee innovation (Baer, 2012). Therefore, the examination of the exchange variables that underlie the relation between CSR and IB may provide an integrative understanding of the specific mechanisms accounting for the way in which job conditions affect employee innovation.

\section{Perceived External Prestige}

From the literature it is apparent that corporate image plays a role in the relationship between CSR and workers' attitudes. Employee commitment to CSR is a complex and multi-faceted phenomenon that is influenced both by corporate contextual factors and by employee perceptions (Collier \& Esteban, 2007). But companies fail to convince stakeholders, and namely, workers, that they are serious about CSR unless they can demonstrate that their policies consistently achieve the desired social, environmental, and ethical outcomes (Collier \& Esteban, 2007). Many companies are realising that having a socially-responsible corporate image is a valuable strategic asset (Kim et al., 2010)

An organisation's PEP or construed image refers to the beliefs held by a member of that organisation concerning what outsiders think of it (Dutton et al., 1994). Hence, PEP is distinguished from organisational reputation, since that refers to outsiders' beliefs about an organisation, whereas the construed external image captures internal members' own assessment of the beliefs held by outsiders about their organisation (Dutton et al., 1994). PEP is, therefore, an indirect means of organisational image-building, since employees establish the image of their organisation through their perception of how outsiders see their firm (Kim et al., 2010). Moreover, employees do pay great attention to CSR initiatives because these societal actions are used by external stakeholders to make character judgements about the organisation's reputation and, by association, that of its members (Roeck \& Delobbe, 2012).

PEP is linked with several positive worker outcomes, for example, if employees believe that outsiders have a positive perception of their company, they are proud of their own affiliation with it (Kim et al., 2010), the more positively employees perceive the external image of their organisation's CSR, the stronger their organisational identification will be (Dutton et al., 1994, Glavas \& Godwin, 2012), and the pride employees obtain by 
working in a respected and prestigious organisation reinforces their self-esteem (Dutton et al., 1994). PEP is also linked with negative outcomes: if members interpret the external organisational image as unfavourable, they may experience depression and stress (Dutton et al., 1994).

It is, therefore, important for managers to cultivate and care for company image and reputation. A bad image can negatively influence company performance, and the literature provides several examples of the impact on worker attitudes of a poor image. Indeed, corporate reputation is a fundamental intangible resource which can be created or depleted as a consequence of the decisions to engage in or shy away from social responsibility activities and disclosure (Branco \& Rodrigues (2006). Workers themselves often possess incomplete information about their company, so it is important to provide them with the right knowledge about their companies' policies and CSR practices. Social responsibility disclosures may then be used by firms as one of the informational signals upon which stakeholders base their assessments of corporate reputation (Branco \& Rodrigues, 2006).

\section{Objective and Hypotheses}

Perceptions of CSR Predicting IB

Innovation refers to the intentional introduction and application within an organization, of ideas, processes, products and/or procedures, new to the unit of adoption, and designed to significantly benefit the organisation or wider society (West \& Farr, 1989). It consists of various practices, such as opportunity exploration, idea generation, championing, and application (de Jong \& Kemp, 2003), and is closely related to employee creativity (de Jong \& Deanne, 2007). IB refers to employee initiatives related to any innovation in the organisation including the generation of new and useful ideas, the communication of ideas and suggestions, and the implementation of ideas (Pundt, 2015). Such behaviours are purely discretionary and not formally recognised by organisational reward systems (Ramamoorthy et al., 2005).

The knowledge about psychology and the nature of IB is two-dimensional. On one hand, the human being is motivated to explore and manipulate the environment in an essentially creative way. On the other, in order to continue with this attitude, the environment needs to be free of threats, and provide the individual with psychological comfort such that s/he feels safe at work (West \& Altink, 1996). Hence, IB may be subject both to internal factors related to the intrinsic individual characteristics, and external factors related to culture or organisational environment.

Numerous surveys and case studies making the argument that companies that are good corporate citizens can attract better talent and have employees that are more motivated, loyal, and innovative (Glavas \& Piderit, 2009). The literature on organisational justice suggests that a procedural justice component may impact upon IB and when employees perceive that their employer has fulfilled his/her obligations, they are more likely to perceive an obligation to engage in discretionary and voluntary behaviours that may be beneficialto the organisation (Ramamoorthy et al., 2005). At the same time, 
Brammer et al. (2015) suggest that CSR is positively related to outcomes such as employee creativity.

Therefore, the following hypothesis is proposed:

- H1: Perceptions of CSR practices have a positive relationship with IB

Perceptions of CSR Predicting OT

As mentioned earlier, social exchanges are of particular importance because they can be decisive to organisational and individual performances. Good quality relationships built on respect and trust are the most important determinants of organisational success (Bello, 2012), and research studies highlight the importance of trust for individual well-being in business environments (Krot \& Lewicka, 2012). Those relations can be used to explain the link between employee perceptions of workplace aspects and their subsequent behaviour. In a review of the SET literature, Tekleab \& Chiaburu (2011) verified that employees who develop high quality exchanges with their organisations reciprocate by displaying positive attitudes. Social exchange requires trusting others, and thus, feelings of obligation and trust are important drivers of the reciprocation of benefits in the social exchange process (Zapata et al., 2013).

Trust involves one's intention to accept vulnerability to a trustee's actions based on the expectation, or belief, that these actions will be beneficial, favourable, or at least not detrimental to one's interest (Colquitt et al., 2007). Krot \& Lewicka (2012) suggest that employees who are treated fairly, perceive their managers as benevolent and, therefore, reliable or trustworthy. Consequently, it can be seen that trust has the power to generate attitudinal and behavioural reciprocation between exchange partners (Tekleab \& Chiaburu, 2011). It usually involves a perception of congruency, or the belief that the trustee adheres to a set of principles and values considered as acceptable by the trustor (Roeck \& Delobbe, 2012).

Perceived CSR sends important signals to employees about an organisation's ethical stance and moral values, and therefore, the extent to which it can be trusted (Roeck \& Delobbe, 2012). CSR may serve as the basis of presumptive trust (Bauman \& Skitka, 2012). Hansen et al. (2011) seem to be the first to have investigated the benefits of CSR initiatives in terms of employees' trust evaluations and subsequent behaviour (Roeck \& Delobbe, 2012), finding that employee OT partially mediates the relationship between CSR and employee attitudinal and behavioural outcomes. Roeck \& Delobbe (2012) find evidence that CSR initiatives can support organisations' efforts to maintain a strong relationship with their employees. Lin (2010) also confirmed that the four dimensions of Corporate Citizenship (economic, legal, ethical, and discretionary) are related to organisational trust and work engagement.

Therefore, the following hypothesis is proposed:

- H2: Perceptions of CSR practices have a positive relationship with OT 
Perceptions of CSR Predicting AC

Organisational Commitment comprises three factors: a strong belief and the acceptance of the organisation's goals and values; a willingness to exert considerable effort on behalf of the organisation; and a definite desire to maintain organisational membership (Porter et al., 1974). Meyer et al. (2002) refer to a three-component model, which distinguishes three forms of Organisational Commitment (an affective component as an emotional attachment, identification and involvement with the organization; a continuance component as personal investment and the costs that employees associate with leaving the organisation; and a normative component as the obligation and moral duty to remain in the organisation). They found that the relationships were stronger between AC and a broad range of desirable variables such as attendance and performance (Meyer et al., 2002).

There are several studies that suggest positive relations between CSR and workers' AC (see for example, Peterson, 2004; Brammer et al., 2007; Turker, 2009a; Aguinis \& Glavas, 2012). Peterson (2004) found that members are prouder to identify with a respectful and socially well-regarded organisation because such affiliation is supposed to boost their self-esteem; Brammer et al. (2007) on the other hand, examined how external CSR, mainly concerned with organisational reputation, is positively related to organisational commitment. And Turker (2009a), also focusing on organisational commitment, found that CSR was a significant predictor of such commitment by social and non-social stakeholders, employees, and customers. In the Portuguese context, Rego et al. (2010) showed that perceptions about Corporate Citizenship predict workers' AC. Individuals develop organisational affective bonds as a way to "pay the debt" they feel for being well treated, respected, and rewarded by their organisations (Rego et al., 2010).

Therefore, the following hypothesis is proposed:

- H3: Perceptions of CSR practices have a positive relationship with AC

OT Predicting AC

Two important variables are crucial in improving employee job performance, OT and employee commitment (Bello, 2012). Whereas OT represents individuals' confidence and expectations about the actions of their organisations, AT reflects their subsequent involvement with and enthusiasm about, the work assigned to them by the organisation, implying the potential influence of the former upon the latter (Lin, 2010).

OT has been studied in Organisational Behaviour as a mediator between mostly internal organisational antecedents like leadership style and personality, and important consequences such as performance, turnover, and organisational commitment (Hansen et al. 2011). As noted earlier, employees who develop high quality exchanges with their organisations reciprocate by displaying positive attitudes, like OT. Those who perceive that the organization has fulfilled its obligations are more likely to be emotionally attached to it (Tekleab \& Chiaburu, 2011). 
As a social exchange construct, OT generates attitudinal and behavioural reciprocation to the focal exchange partner (Tekleab \& Chiaburu, 2011), employees reciprocate by staying in the organisation, showing more job satisfaction and AC. OT also increases employee commitment and productivity (Krot \& Lewicka, 2012).

Therefore, the following hypothesis is proposed:

- H4: OT has a positive relationship with AC

\section{OT Predicting HAP}

The study of HAP is very important in organisational behaviour. Lyubomirsky et al. (2005) reported that individuals high in subjective well-being are more likely to be evaluated more positively by supervisors, to show superior performance and productivity, and to handle managerial jobs better, and are also less likely to show counterproductive workplace behaviour and job burnout. Studying HAP is valuable for several reasons, being: valuable per se; associated with higher performance and better organisational functioning; and a fundamental ingredient of the "good life and good society" (Rego et al., 2011).

The last decades have witnessed an explosion of research on HAP and subjective well-being (Lyubomirsky \& Lepper, 1999; Spagnoli et al., 2012). Research has shown some relationships between OT and well-being (Ashleigh et al., 2012). HAP is a subjective experience: people are happy to the extent that they believe themselves to be happy (Rego et al., 2011). Scholars tend to treat happiness as psychological well-being, a multidimensional construct covering several components, including affective well-being, competence, aspiration, autonomy, integrative functioning, and satisfaction (Rego et al., 2011). Positive emotions produce the tendency to approach rather than to avoid and to prepare the individual to seek out and undertake new goals (Lyubomirsky et al., 2005).

High levels of OT in management enable employees to feel less threatened during organisational changes and exert positive effects on employees' well-being (Russel, 2008). Also stronger feelings of gratitude toward the organization and its members are evident, and such feelings may increase their well-being (Rego, et al. (2011).

Therefore, the following hypothesis is proposed:

- H5: OT has a positive relationship with HAP

\section{AC Predicting IB}

Several authors (Eisenberger \& Fasolo, 1990; Wenhua, 2011; Xerri \& Brunetto, 2013: Montani et al., 2017) have found that IB is positively related to AC. That is to say, a worker who feels an affective attachment will invest in the organisation's success by making more suggestions, participating more in innovative activities and use his/her intellect to promote organisational innovation. 
From a social exchange perspective, employees with strong AC might be expected to invest in creating and applying novel solutions that are intended to improve organisational effectiveness (Montani et al., 2017). Employees who are affectively committed tend to be concerned about the organisation's well-being and are also more inclined to support the organisation's strategic direction by approaching workplace problems innovatively (Xerri \& Brunetto, 2013). Employees who receive pleasurable and challenging job conditions from an organisation tend to feel a sense of concern for the organisation's well-being through AC, and this in turn, enhances employees' willingness to engage in behaviours that benefit the organisation (Montani et al., 2017).

Eisenberger and Fasolo (1990) found that employees' general perception of being valued and cared for by their organisations was positively related to $\mathrm{AC}$, and to their efforts to innovate on behalf of them. In a focus on individual workers' psychological outcomes, Wenhua (2011) found that a significantly positive correlation exists between AC and IB, with the former having a strong positive effect on the latter. Similar results were obtained by Xerri and Brunetto (2013) who found IB to be positively related to AC.

Therefore, the following hypothesis is proposed:

- H6: AC has a positive relationship with IB

\section{HAP Predicting IB}

Russel (2008) reported a positive relationship between subjective well-being and a successful working life (with positive effect on job satisfaction, work performance, greater customer satisfaction and loyalty, greater profitability, more productivity, and lower rates of turnover, among other outcomes). And Fredrickson (2011) theorised that positive emotions actively broaden the scope of attention and cognition, enabling flexible and creative thinking that subsequently guide individual behaviour in the moment.

Numerous studies have also been identified by Lyubomirsky et al. (2005), which indicate that HAP and positive affect positively impact upon creativity, flexible thinking, and originality. Likwise, Amabile et al. (2005) have also demonstrated that positive affect relates positively to creativity in organisations and that the relationship is a simple linear one. In the process, positive affect makes additional cognitive material available for processing, leads to defocused attention increasing cognitive flexibility, and the probability that diverse cognitive elements will in fact become associated. Amabile et al. (2005) proposed a creativity cycle, where affective states that follow from an idea's reception by others in the organisation may give rise to subsequent changes in cognition and creativity. Isen and Reeve (2005) have also shown that positive affect facilitates flexible thinking and problem-solving, and enhances performance, even where the tasks to be done are complex, difficult, and important.

Therefore, the following hypothesis is proposed: 
- H7: HAP has a positive relationship with IB

PEP as a Moderator of Employees' Responses to CSR

Research has suggested the existence of an association between PEP and CSR. Branco and Rodrigues (2006), for instance, affirm that the external benefits of CSR are related to its effect on corporate reputation, and that good social responsibility reputation may also attract better employees or increase current employees' motivation, morale, commitment, and loyalty to the firm. And Carmeli et al. (2007) observe that favourable PEP is seen in the form of CSR. Rego et al. (2010_ explain that PEP (of working in an organisation with high performance and dedication to customers) may also explain the relationship between perceptions of economic CSR and AC. Furthermore, Roeck and Delobbe (2012) suggest that CSR initiatives can reflect a positive organisational image that enhances employees' pride and willingness to be associated with such a reputable organisation.

CSR research has distinguished between alternative motivations for engaging in responsible activities and practices, especially between instrumental approaches to CSR whereby organisations seek to benefit from responsible conduct, and altruistic motivations for CSR in which there are no anticipated benefits (Brammer et al., 2015). Employees form PEP through outside information sources such as reference groups, word of mouth, publicity, and internal communication about how non-company employed persons perceive the firm (Kim et al., 2010). Using these sources, employees formulate their perceptions of CSR and evaluate organisational intentions and social values, determining whether they are congruent with their personal objectives and values.

Considering this fact, we hypothesise that where employees perceive firms' CSR to be significantly higher than PEP (bad company image situation), they will interpret such CSR as being instrumentally motivated. In such circumstances, CSR will have a significantly reduced effect on IB compared with circumstances in which CSR and PEP are approximately equal or where PEP is higher than CSR (good company image situation).

Therefore, the following hypotheses are proposed:

- H8: PEP moderates the relationship between CSR and IB, such that CSR more positively influences IB when PEP is stronger rather than weaker.

- H9: PEP moderates the relationship between CSR and the social exchange process in organisations, such that when PEP is weaker the reactions to CSR are more significant.

\section{Data and Methods}

\section{Sample}

In order to test the research hypotheses, data was obtained from a sample of 315 individuals providing valid responses, and generating a real response rate of $11.25 \%$. This sample of 315 individuals ( $43 \%$ female), were on average 40 years old, and had an average 
tenure of 13 years in a wide range of positions (e.g., administrative staff, customer services, salespersons, consultants, bank clerks, assistants, accountants, managers), and $82 \%$ held a bachelor's degree or higher. Of the companies where respondents worked, $23.5 \%$ were from services, $56.5 \%$ from industry, and $20 \%$ from trade. Their size was measured as the number of workers, and in this respect, $42.1 \%$ were small (less than 50 workers), 42,3\% were medium (between 51 and 250 workers), and 15.6\% were big (more than 250 workers).

\section{Instrument}

In order to test the hypotheses and the validity of the model under investigation, a quantitative cross-sectional study based on a questionnaire with closed questions was conducted. An online survey was used to collect the data. The variables were operationalised through scales reported in the literature. Respondents were asked to indicate their level of agreement with the different measures on a five-point Likert scale (1 - Totally disagree to 5 - Totally agree).

The measures that were used are as follows:

CSR (predictor variable) seeking to assess the business responsibilities of various stakeholders was evaluated by a scale adapted from Turker (2009b). In this framework, CSR practices were measured using 20 questions sub-divided into the following four dimensions: Social and non-social stakeholders (CSR1), Employees (CSR2), Customers (CSR3), and Government (CSR4). All dimensions revealed adequate levels of reliability (CSR1 $\alpha=0.87$, e.g., "Our company makes investment to create a better life for the future generations"; CSR $2 \alpha=0.89$, e.g., "Our company implements flexible policies to provide a good work and life balance for its employees"; CSR3 $\alpha=0.76$, e.g., "Our company protects consumer rights beyond the legal requirements"; CSR $4 \alpha=0.89$, e.g., "Our company complies with the legal regulations completely and promptly").

IB comprehending the individual actions directed at the generation, introduction and application of beneficial novelty at any organisational level, was measured by an 8-item scale from de Jong and Kemp (2003) (e.g., "In my work, I often come up with ideas"; $\alpha=0.90$ ).

OT reflecting employees' perceptions of their employer in terms of integrity, motives, intentions, and dependability was evaluated by using the 7-item scale of Robinson and Rousseau (1994) (e.g., "In general, I believe my employer's motives and intentions are good"; $\alpha=0.91)$.

AC was measured with three items previously developed and validated in the Portuguese context by Rego et al. (2007). The scale revealed good reliability ( $\alpha=0.92$, e.g., "I am proud to tell others that I am part of this organisation").

HAP a concept similar to subjective well-being, was measured by adapting the 4-item scale of Lyubomirsky and Lepper (1999), with one item for the assessment of life as a whole, one item for personal well-being, another for health perception, and another for 
quality of life. The scale also revealed good reliability $(\alpha=0.73$, e.g., "Compared to most of my peers, I consider myself more happy").

In order to measure the way in which employees believe outsiders see their organisation (PEP), three items from the scale of Mael and Ashforth (1992), and two items from the scale of Kim et al. (2010) were merged to form 5-item scale. (e.g., "My company is considered as one of the best in the society"; $\alpha=0.88$ ).

It was also considered important to include socio-demographic variables to achieve consistency in results, and to validate the quality of answers. In this respect, respondents were asked to provide information about their sex, age, function, antiquity, ???? and school level.

\section{Procedure}

To gather the required information, a database of email contacts of Portuguese companies was used. Each contact was sent an email explaining the nature and importance of the study and providing a link to access the online survey. The research and delivery of the email was implemented between 19 March and 19 August 2013, and a total of 2,800 contacts were used.

\section{Results}

\section{Descriptive Statistics}

Table 1 presents means, standard deviations, Cronbach's alpha coefficients, and correlations of all key variables.

In general all variables correlate positively.

\begin{tabular}{|c|c|c|c|c|c|c|c|c|c|c|c|}
\hline & M & SD & 1 & 2 & 3 & 4 & 5 & 6 & 7 & 8 & 9 \\
\hline 1. CSR1 & 3,57 & 0,85 & (0.87) & & & & & & & & \\
\hline 2. CSR2 & 3,83 & 0,75 & $.60 * *$ & (0.89) & & & & & & & \\
\hline 3. CSR3 & 4,46 & 0,58 & $.38 * *$ & $.65^{* *}$ & $(0.76)$ & & & & & & \\
\hline 3. CSR4 & 4,64 & 0,63 & $.33 * *$ & $.47 * *$ & $.52 * *$ & (0.89) & & & & & \\
\hline 5. OT & 4,06 & 0,78 & $.36^{* *}$ & $.71^{* *}$ & $.51^{* *}$ & $.50 * *$ & $(0.91)$ & & & & \\
\hline 6. AC & 4,41 & 0,68 & $.44 * *$ & $.69 * *$ & $.56^{* *}$ & $.51 * *$ & $.72 * *$ & $(0.92)$ & & & \\
\hline 7. PEP & 4,05 & 0,63 & $.57 * *$ & $.52 * *$ & $.40 * *$ & $.45^{* *}$ & $.45^{* *}$ & $.50 * *$ & $(0.88)$ & & \\
\hline 8. HAP & 3,82 & 0,59 & $.15^{* *}$ & $.21 * *$ & .11 & $.14^{*}$ & $.25^{* *}$ & $.23 * *$ & $.26^{* *}$ & $(0.73)$ & \\
\hline 9. IB & 4,12 & 0,56 & $.19 * *$ & $33^{* *} *$ & $.31 * *$ & $.25 * *$ & $.33^{* *}$ & $.40 * *$ & $.30 * *$ & $.31 * *$ & $(0.90)$ \\
\hline
\end{tabular}

Note: Five Point Scale: ${ }^{*} p<0.05 ;{ }^{* *} p<0.01$ two-tailed; Cronbach-alphas in parentheses;

\section{Hypotheses Tests}

We used the statistic software IBM SPSS Statistics 20.0 to perform descriptive statistics, correlations, and confirmatory factor analysis. Amos 20.0 was used to perform 
confirmatory factor analysis and structural equation modelling (SEM). We examined model fit using the following indices: $\chi 2, \chi 2 / \mathrm{df}$, root mean square error of approximation (RMSEA), relative fit index (RFI), comparative fit index (CFI), normed fit index (NFI), and Tucker-Lewis index (TLI). In making fit determinations, we used generally accepted thresholds (see Maroco, 2010) which suggested reasonably fitting models that typically characterised $\chi 2 / \mathrm{df}$ as high as 5, RMSEA values as high as 0.08 , and RFI, CFI, NFI, and TLI values of 0.90 or higher.

We conducted a confirmatory factor analysis for the model with all nine variables, the fit indices were (e.g., $\chi 2 / \mathrm{df}=1.942, \mathrm{RFI}=0.818, \mathrm{CFI}=0.910, \mathrm{NFI}=0.832, \mathrm{TLI}=0.903$, RMSEA $=0.055$ ), and these were considered unsatisfactory. By analysing the standardised residuals and modification indices for the sources of misspecification, eleven items were removed and a well-fitting 37-item model with nine dimensions emerged (e.g. $\chi 2 / \mathrm{df}=$ 1.644, RFI=0.877, CFI $=0.954, \mathrm{NFI}=0.890, \mathrm{TLI}=0.948, \mathrm{RMSEA}=0.045$ ).

All factor loadings and AVE values for latent construct variables (i.e., CSR, OT, AC, HAP and IB) were above recommended cut-off levels (i.e., AVE above 0.5; see Maroco, 2010) providing initial evidence of valid measurement models (see Table 2). The AVE value for each variable was greater than the square of the correlation between each variable and all other variables in its respective measurement model, providing additional evidence of validity (Fornell \& Larcker, 1981).

To minimise the risk of common method variance we used some procedural methods and statistical controls as proposed by Podsakoff et al. (2003): respondents were guaranteed anonymity and confidentiality, were told that there were no right or wrong answers, and there was randomness in the ordering of the multiple items. Harman's single factor test (Podsakoff \& Organ, 1986) was performed. The single factor model also did not fit the data satisfactorily (e.g. $\chi 2 / \mathrm{df}=6.667, \mathrm{RFI}=0.500, \mathrm{CFI}=0.566, \mathrm{NFI}=0.528$, TLI $=0.541$, RMSEA $=0.34$ ). A principal component analysis (unrotated solution) on all the variables revealed eigenvalues greater than 1 . They accounted for $69.97 \%$ of the total variance, with seven factors, the first of which explained $37.24 \%$ of the variance. This suggested that common method bias was not a serious problem for the data and was not, therefore, a serious threat to the validity of the study. 


\begin{tabular}{|c|c|c|c|c|c|c|c|c|c|}
\hline $\begin{array}{c}\text { Latent } \\
\text { Construct }\end{array}$ & $\mathrm{AVE}$ & Reliability & Items & $\begin{array}{c}\mathrm{N}=315 \\
\text { Loadings }\end{array}$ & $\begin{array}{c}\text { Latent } \\
\text { Construct }\end{array}$ & $\mathrm{AVE}$ & Reliability & Items & $\begin{array}{c}\mathrm{N}=315 \\
\text { Loadings }\end{array}$ \\
\hline \multirow{4}{*}{ CSR1 } & \multirow{4}{*}{0.723} & \multirow{4}{*}{0.868} & RS2 & 0.872 & & & & PEP3 & 0.821 \\
\hline & & & RS3 & 0.832 & PEP & 0.796 & 0.938 & PEP4 & 0.923 \\
\hline & & & RS4 & 0.898 & & & & PEP5 & 0.929 \\
\hline & & & RS6 & 0.794 & & & & HAP1 & 0.828 \\
\hline \multirow{3}{*}{ CSR2 } & \multirow{3}{*}{0.788} & \multirow{3}{*}{0.865} & RS9 & 0.910 & HAP & 0.654 & 0.730 & HAP2 & 0.799 \\
\hline & & & RS10 & 0.872 & & & & HAP3 & 0.801 \\
\hline & & & $\mathrm{RS} 12$ & 0.881 & & & & $\mathrm{ACl}$ & 0.900 \\
\hline \multirow{3}{*}{ CSR3 } & \multirow{3}{*}{0.676} & \multirow{3}{*}{0.755} & RS13 & 0.738 & & & & $\mathrm{AC} 2$ & 0.925 \\
\hline & & & RS14 & 0.640 & AC & 0.752 & 0.917 & $\mathrm{AC} 4$ & 0.894 \\
\hline & & & RS16 & 0.776 & & & & $\mathrm{AC} 4$ & 0.895 \\
\hline \multirow{3}{*}{ CSR4 } & \multirow{3}{*}{0.728} & \multirow{3}{*}{0.888} & RS17 & 0.813 & & & & AC5 & 0.703 \\
\hline & & & RS18 & 0.792 & & & & IB1 & 0.774 \\
\hline & & & RS19 & 0.860 & & & & IB2 & 0.824 \\
\hline \multirow{6}{*}{ OT } & \multirow{6}{*}{0.771} & \multirow{6}{*}{0.938} & OT1 & 0.829 & & & & IB3 & 0.829 \\
\hline & & & OT2 & 0.840 & IB & 0.641 & 0.906 & IB4 & 0.788 \\
\hline & & & OT3 & 0.914 & & & & IB5 & 0.835 \\
\hline & & & OT4 & 0.896 & & & & IB6 & 0.819 \\
\hline & & & OT5 & 0.928 & & & & IB7 & 0.728 \\
\hline & & & от6 & 0.857 & & & & & \\
\hline
\end{tabular}

To test the hypotheses we analysed the structural equation model. The final model showed a good fit (e.g., $\chi 2 / \mathrm{df}=1.969, \mathrm{RFI}=0.781, \mathrm{CFI}=0.889, \mathrm{NFI}=0.800$, TLI= 0.879, RMSEA $=0.039$. A multi group analysis was performed to identify the differences between workers who show different sensitivity to PEP. The cut point was 4 or less in the 5-point Likert scale used to measure PEP. So, the first group comprised of those who have a low company image, included 179 workers, while the second group containing those who have a high image numbered 136. Table 3 presents the final results:

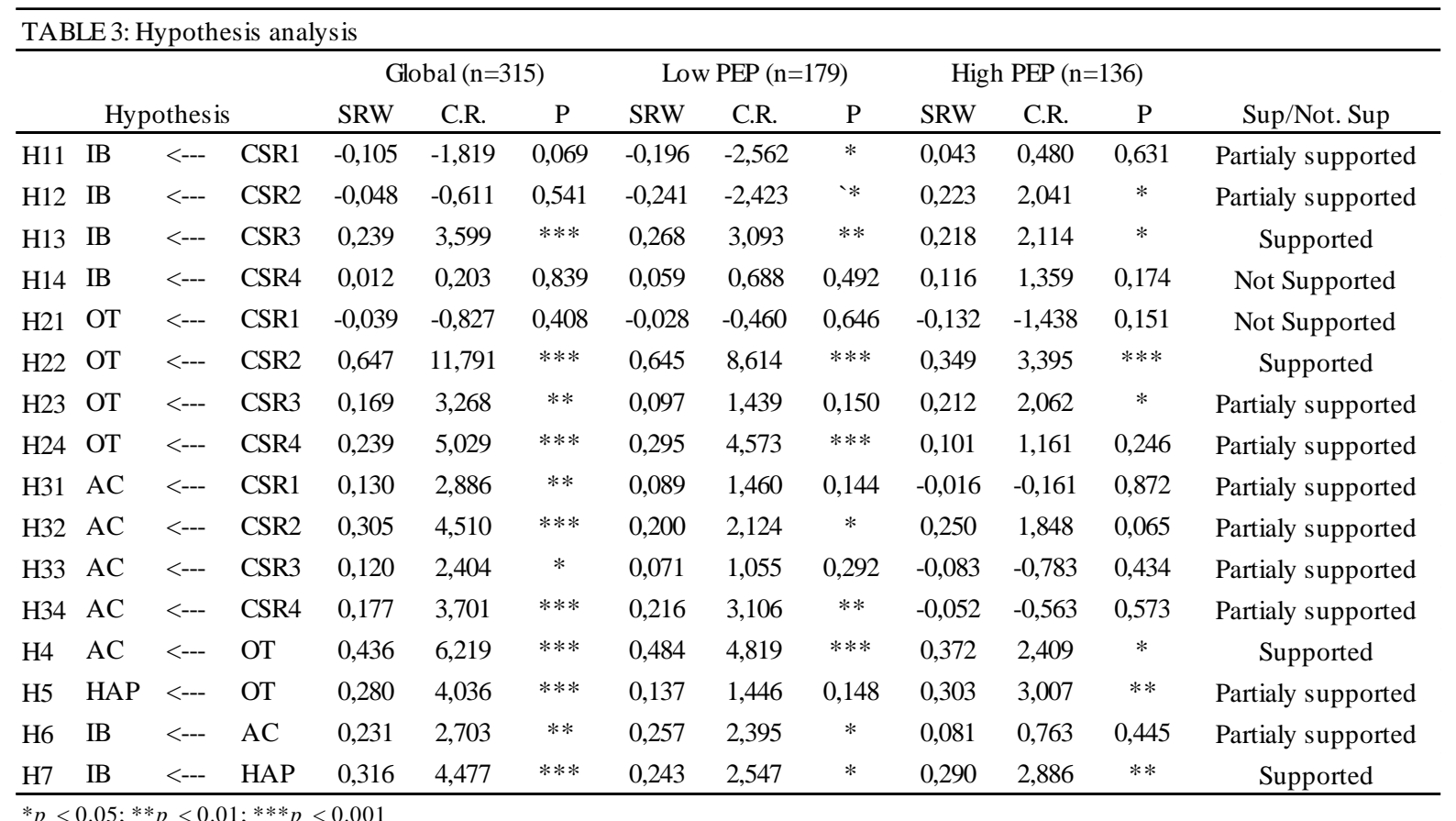


There is a positive relationship between CSR perceptions and IB but only on the customer's dimension of CSR. The social and non-social stakeholder, employees and government dimensions do not seem to have a significant relationship with IB. However, when we proceed to analyses between groups we find that the results are the opposite. The group with a bad company image seem to be more sensitive to CSR practices (CSR1, CSR2 and CSR3 are significant). In this group CSR1 and CSR2 have a negative relationship with IB. In the group with a good company image only CSR2 and CRS3 have a positive relationship with IB. Consequently, hypothesis H1 is only partially supported, and hypothesis $\mathrm{H} 8$ is supported.

There is a positive relationship between CSR perceptions and OT. All dimensions except social and non-social stakeholder are significant. The employee dimension is the one where the relationship is stronger. The results are similar for both groups, with bad and good company image. However, the group with a bad company image seems to be more sensitive to CSR practices. We also observe that in the group with a bad company image there is a positive relationship between CSR2 and CSR4 with OT. In the other group the positive relationship is between CSR2 and CSR3 with OT. Consequently, hypothesis H2 is only partially supported.

There is also a positive relationship between CSR perceptions and AC. All dimensions are significant. The employee dimension is again the one where the relationship is stronger. However, when we proceed to analyses between groups we find that the results are different. The group with the bad company image seem to be more sensitive to CSR practices (CSR2 and CSR4 are significant). In respect of the group with a good image this relationship does not seem to be significant; only CSR2 is near with $p=0,065$ from $p<0,05$ level of significance. Consequently, hypothesis $\mathrm{H} 3$ is only partially supported.

In general, and considering the effects of CSR on IB, OT and AC, we can see that they are strong and mainly positive. Analysing the differences by groups, the relationships seems to be stronger with the bad company image group (hypothesis H9 is supported). The results also show that the good company image group only care for CSR2 because this is almost the only significant dimension. The group with a bad image is more sensitive to CSR because all dimensions are significant. We also notice a negative relationship between $\mathrm{CSR}$ and IB in the group with a bad company image.

Hypothesis $\mathrm{H} 4$ is supported, as it confirms a positive relationship between OT and AC. The results are similar for both groups, i.e., those with a bad, and a good company image. However, the relationships in the former group (bad image) seem to be stronger.

We found a significant positive relationship between OT and HAP. However, when we proceed to analyse between groups we find that the results are different, being significant in the good company image group, and not significant in the other. Consequently, H5 is only partially supported.

We also found a significant positive relationship between HAP and IB. However, when we proceed to analyse between groups we find that the results are different, being 
significant in the bad company image group, and not significant in the other. Consequently, hypothesis H6 is only partially supported.

Hypothesis H7 is supported, as a positive relationship between HAP and IB is found. The results are similar for both groups, with a bad and good company image. However, the relationships in the group with the bad company image seem to be stronger.

The findings show that perceptions of CSR predict IB through a social exchange process in which there is a mediating role of OT, AC and HAP. From the data we found differences between groups suggesting that Perceived External Prestige (PEP) moderates the relationship between IB and its determinants.

Analysing the differences between groups it is important to remember that in general, workers who have a bad image of the company are more influenced by CSR practices.

However, in the context of a bad company image, the influence of CSR practices does not accord with the theory, but rather takes the opposite direction. The influence on IB seems to be negative. Workers react negatively to CSR. We also found that in respect of predictig IB, the group with the bad company image involves OT and AC in its social exchange process. However, because HAP is not influenced by OT we consider this process to be more focused on $\mathrm{AC}$; this is to say that IB is more influenced by individual characteristics (AC) than by organisational characteristics (PEP, CSR).

The social exchange process observed in the group with the good company image is mainly concerned with OT and not AC. Whereas OT is influenced by CSR, AC is not. HAP is also influenced by OT, and consequently, relates positively with IB. Therefore, we consider this process to be more focused on OT; this is to say that IB is more influenced by organisational characteristics (PEP, CSR) than by individual characteristics (AC).

\section{Discussion and Conclusions}

The findings suggest that employee perceptions about CSR responsibilities are important and affect their IB. The results of the tested hypotheses showed that employees are aware when corporations promote social responsibility practices and value these aspects: in these circumstances they reported a direct influence upon innovation (even if the significance of all CSRs was not obtained) and an indirect influence through the mediating mechanisms (OT, AC and HAP).

These findings are naturally positive and the hypothesised links are consistent with the literature. CSR can be an effective way for firms to maintain a positive relationship with their employees (Kim et al., 2010). IB is positively influenced by perceptions of CSR practices (Glavas \& Piderit, 2009; Brammer et al., 2015). A worker who perceives that the organisation cares for CSR issues appears to be more innovative, to use his/her knowledge to create new ideas, and to be engaged in the process of integrating new problem-solving ideas within existing organisational practice. 
Regarding the moderating effect of PEP, it was interesting to confirm hypothesis $\mathrm{H} 8$ to the effect that PEP moderates the relationship between CSR and IB, and the negative influence of CSR on IB in the group with the bad company image. This fact highlights the importance of PEP and indicates that workers are very sensitive to organisational reputation. Therefore, and given the association that emerged between CSR and PEP, it is important to ensure that employees are among the stakeholders included in corporate communication about CSR activities (Kim et al., 2010).

Concerning social exchange, the findings suggest that the relationship between CSR and IB was mediated by OT, AC and HAP. We concluded that OT is positively influenced by perceptions of CSR practices (Hansen et al., 2011; Roeck \& Delobbe, 2012); that is to say that individuals appear to trust more when working for socially responsible organisations, and have more intentions to accept the vulnerability to a trustee based on positive expectations of his or her actions. AC is also positively influenced by perceptions of CSR practices (Turker, 2009a; Aguinis \& Glavas, 2012). A worker who perceives that the organisation cares for CSR issues appears to be more emotionally attached to the organisation, identifies more with organisational values, and is more involved.

The findings also confirmed the positive influence of OT on AC and HAP, an outcome consistent with the results of previous studies undertaken by Krot and Lewicka (2012), and Rego et al. (2011). The findings demonstrate that for an affective attachment and healthy and happy workplace, building trust among employees is essential. And according to the findings, both these factors AC and HAP seem to influence IB. Montani et al. (2017) observe that AC entails positive emotions which may feed individual innovation, and positive affective states induce flexible thinking that is useful for producing novel ideas and creative outcomes.

Regarding the moderation effect of PEP, it was interesting to confirm hypotheses H9 that PEP moderates the relationship between CSR and the social exchange process in organisations, such that when PEP is weaker, the reactions to CSR are more significant. This fact seems to induce a slight indifference among workers to CRS when corporate image is acceptable or good, but not when workers possess a bad company image. They seem to react more strongly to CSR when corporate image is weaker, but this brings the problem that they may feel like the victims of an unbalanced social exchange (Robinson, 2008), and likely try to restore the balance by showing less concern for the organisation's well-being, ultimately engaging in less innovative action (Montani et al., 2017).

\section{Theoretical Contributions}

This study responds to a call from researchers who have argued that more empirical research is necessary to understand the underlying mechanisms explaining how CSR influences employee behaviour (Roeck \& Delobbe, 2012; Glavas, 2016).

The present investigation presents two major contributions. The first one relates to the identification of the influence of CSR practices on workers' IB through a social exchange process that involves OT, AC and HAP. Brammer et al. (2015) suggested that future 
research should move toward a better and more complete understanding of the outcomes of CSR by examining the "black box" concealing the way in which CSR affects organisational outcomes. They encouraged efforts to examine simultaneously, different psychological mechanisms like social exchange. Our research has responded to this call and provided evidence about the importance of social exchange in the relationship between CSR and employee creative effort.

The second contribution is related to the introduction of the role of PEP as a moderating variable. To our knowledge, studies of PEP in the relationship between CSR and IB is scarce. This dimension has been investigated more as a mediator between CSR and other employee outcomes like: commitment, identification, job satisfaction, motivation, morale, and loyalty, among others. Specifically, in this study, theoretical integration has allowed for the clear identification of PEP as a moderating mechanism in the link between CSR practices and IB.

\section{Implications for Management}

The overall achievements in this investigation are conclusive and contribute to a better understanding of CSR and its influence upon employee IB.

Specifically, the research outcomes suggest that organisations should not discharge their CSR sporadically but should rather do this systematically, promoting CSR practices to a wide range of stakeholders: social and non-social stakeholders, employees, customers, and government. By showing that the perceptions of CSR predict IB, either directly or through the mediating role of OT, AC and HAP, this study provides practitioners with strategies to guarantee good results at the individual level and, consequently, at the organisational level. The research has also highlighted the importance of PEP and the strategic importance of maintaining or achieving a good corporate image.

We reinforce the conclusion arrived at by Hansen et al. (2011), that if CSR is important to employees, then it should also be important to employers. By fostering CSR practices, the investment can pay off internally. Hence, managers could expect good outcomes for the internal stakeholders. Furthermore, despite the effect of CSR on IB not being revealed as directly intense, CSR does contribute strongly to the solidification of the social exchanges that occur between organisations and workers. CRS can contribute to a virtuous circle of more trust, more commitment, more happiness, and more innovation.

However, for CSR to have meaningful and desirable impacts on workers, those workers must have full knowledge of their companies' CSR activities (Brammer et al., 2015). Also, given the strategic importance of PEP it is important for managers to invest in disclosure. In this connection, there are various media, including advertisements, promotions, newsletters, and sustainability CSR reports, that can help deliver a positive company image to employees (Kim et al., 2010). And the benefits of improving stakeholders' perceptions of their corporate image by satisfying social informative needs are likely to be greater than the information costs (Alvarez, 2015). 


\section{LIMITATIONS AND RECOMENDATIONS}

A study of this nature faces several methodological limitations affecting its contribution. In this case, it should be noted that we were working on 'perceptions', which we clarify as the process by which the individual organises and interprets sensory impressions in order to provide meaning to the surrounding environment. It is observed that the subject can perceive a reality substantially different from the objective reality. It is also possible that a respondent will provide incorrect or incomplete information. Hence, the investigators are obliged to work in a diffuse reality and not on facts.

Measuring IB via self-report may also be seen as a limitation. However, several arguments support using such a measure (Pundt, 2015): employees have more valid information about their subtle innovative efforts than anyone else does, self-reports of discretionary behaviour such as IB can be better distinguished from in-role performance, and studies on organisational silence show that employees often decide not to communicate the ideas they have and this means that some elements of IB are unobservable.

Another issue is the fact that the dependent and independent variables are taken simultaneously (common-source data), increasing the risk of common method variance (Podsakoff \& Organ, 1986), such that the statistical relationships found could be inflated. We must also be aware that the use of cross-sectional research design does not allow the drawing of firm conclusions about the causality nexus between the study variables. Other causal links are also plausible; in the specific context of this study, it is possible that workers who have more IB could have higher perceptions of CSR practices.

As for recommendations for future work, in terms of the social exchanges explored, beyond OT and $\mathrm{AC}$, there are other social exchanges that could be analysed, namely: psychological contract fulfilment, perceived organisational support, and leader member exchange.

Despite the limitations identified, the study confidently suggests that individuals are affected by CSR practices and by PEP, and that both these variables are important in generating positive worker behaviours like IB.

\section{References}

Aguinis, H. and Glavas, A. (2012) 'What we know and don't know about corporate social responsibility: a review and research agenda', Journal of Management, Vol. 38, No. 4, pp.932-968.

Alvarez, A. (2015) 'Corporate response to human resource disclosure recommendations', Social Responsibility Journal, Vol. 11, No. 2, pp.306-322.

Amabile, T. (1998) 'A model of creativity and innovation in organizations', Research in Organizational Behavior, Vol. 10, No. 1, pp.123-167.

Amabile, T., Barsade, S., Mueller, J. and Staw, B. (2005) 'Affect and creativity at work', Administrative Science Quarterly, Vol. 50, No. 3, pp.367-403.

Ashleigh, M., Higgs, M. and Dulewicz, V. (2012) 'A new propensity to trust scale and its 
relationship with individual well-being: implications for HRM policies and practices', Human Resource Management Journal, Vol. 22, No. 4, pp.360-376.

Baer, M. (2012) 'Putting creativity to work: the implementation of creative ideas in organizations', Academy of Management Journal, Vol. 55, No. 5, pp.1102-1119.

Bauman, C. and Skitka, L. (2012) 'Corporate social responsibility as a source of employee satisfaction', Research in Organizational Behavior, Vol. 32, No. 1, pp.63-86.

Bello, S.M. (2012) 'Impact of ethical leadership on employee job performance', International Journal of Business and Social Science, Vol. 3, No. 11, pp.228-236.

Brammer, S., He, H. and Mellahi, K. (2015) 'Corporate social responsibility, employee organizational identification, and creative effort: the moderating impact of corporate ability', Group and Organization Management, Vol. 40, No. 3, pp.323-352

Brammer, S., Millington, A. and Rayton, B. (2007) 'The contribution of corporate social responsibility to organizational commitment', International Journal of Human Resource Management, Vol. 18, No. 10, pp.1701-1719.

Branco, M. and Delgado, C. (2011) 'Research on corporate social responsibility and disclosure in Portugal', Social Responsibility Journal, Vol. 7, No. 2, pp.202-217.

Branco, M. and Rodrigues, L. (2006) 'Corporate social responsibility and resource-based perspectives', Journal of Business Ethics, Vol. 69, pp.111-132.

Carmelli, A., Meitar, R. and Weisberg, J. (2006) 'Self-leadership skills and innovative behaviour at work', International Journal of Manpower, Vol. 27, No. 1, pp.75-90.

Carroll, A. (1979) 'A three-dimensional conceptual model of corporate performance', Academy of Management Review, Vol. 4, No. 4, pp.497-505.

Carroll, A. and Shabana, K. (2010) 'The business case for corporate social responsibility: a review of concepts, research and practice', International Journal of Management Reviews, Vol. 12, No. 1, pp.85-105.

Collier, J. and Esteban, R. (2007) 'Corporate social responsibility and employee commitment', Business Ethics: A European Review, Vol. 16, No. 1, pp.19-33.

Colquitt, J., Scott, B. and LePine, J. (2007) 'Trust, trustworthiness, and trust propensity: a meta-analytic test of their unique relationships with risk taking and job performance', Journal of Applied Psychology, Vol. 92, No. 4, pp.909-927.

Cravens, K. and Oliver, E. (2006) 'Employees: the key link to corporate reputation management', Business Horizons, Vol. 49, No. 4, pp.293-302.

de Jong, J. and Deanne, N. (2007) 'How leaders influence employees' innovative behavior', European Journal of Innovation Management, Vol. 10, No. 1, pp.41-64.

de Jong, J. and Kemp, R. (2003) 'Determinants of co-workers' innovative behaviour: an investigation into knowledge intensive services', International Journal of Innovation Management, Vol. 7, No. 2, pp.189-212.

De Roeck, K. and Delobbe, N. (2012) 'Do environmental CSR initiatives serve organizations' legitimacy in the oil industry? Exploring employees' reactions through organizational identification theory', Journal of Business Ethics, Vol. 110, No. 4, pp.397412.

Dutton, J., Dukerich, J. and Celia V. (1994) 'Organizational images and member identification', Administrative Science Quarterly, Vol. 39, No. 2, pp.239-263.

Eisenberger, R. and Fasolo, P. (1990) 'Perceived organizational support and employee diligence, commitment, and innovation', Journal of Applied Psychology, Vol. 75, No. 1, pp.51-59. 
European Commission (2011) A renewed EU strategy 2011-14 for Corporate Social Responsibility, 25 October, Brussels.

Fornell, C. and Larcker, D. (1981) 'Evaluating structural equation models with unobservable variables and measurement error', Journal of Marketing Research, Vol. 18, No. 1, pp.39-50.

Fredrickson, B. (2001) 'The role of positive emotions in positive psychology: the broaden-and-build theory of positive emotions', The American Psychologist, Vol. 56, No. 3, pp.218-226.

Glavas, A. (2016) 'Corporate social responsibility and organizational psychology: an integrative review', Frontiers in Psychology, Vol. 7, No. 144, pp.1-13

Glavas, A. and Godwin, L. (2012) 'Is the perception of 'goodness' good enough? Exploring the relationship between perceived corporate social responsibility and employee organizational identification', Journal of Business Ethics, Vol. 114, No. 1, pp.15-27.

Glavas, A. and Piderit, S. (2009) 'How does doing good matter? Effects of corporate citizenship on employees', Journal of Corporate Citizenship, Vol. 2009, No. 36, pp.51-70.

Hansen, S., Dunford, B., Boss, A., Boss, R. and Angermeier, I. (2011) 'Corporate social responsibility and the benefits of employee trust: a cross-disciplinary perspective', Journal of Business Ethics, Vol. 102, No. 1, pp.29-45.

Herrbach, O. and Mignonac, K. (2004) 'How organisational image affects employee attitudes', Human Resource Management Journal, Vol. 14, No. 4, pp.76-88.

Isen, A. and Reeve, J. (2005) 'The influence of positive affect on intrinsic and extrinsic motivation: facilitating enjoyment of play, responsible work behavior, and self-control', Motivation and Emotion, Vol. 29, No. 4, pp.297-325.

Kim, H., Lee, M., Lee, H. and Kim, N. (2010) 'Corporate social responsibility and employee-company identification', Journal of Business Ethics, Vol. 95, No. 4, pp.557569.

Krot, K. and Lewicka, D. (2012) 'The importance of trust in manager-employee relationships', International Journal of Electronic Business Management, Vol. 10, No. 3, pp.224-233.

Lin, C. (2010) 'Modeling corporate citizenship, organizational trust, and work engagement based on attachment theory', Journal of Business Ethics, Vol. 94, No. 4, pp.517-531. Lyubomirsky, S. and Lepper, H. (1999) 'A measure of subjective happiness: preliminary re-liability and construct validation', Social Indicators Research, Vol. 46, No. 2, pp.137155.

Lyubomirsky, S., King, L. and Diener, E. (2005) 'The benefits of frequent positive affect: does happiness lead to success?', Psychol Bull., Vol. 131, No. 6, pp.803-855.

Mael, F. and Ashforth, B. (1992) 'Alumni and their alma mater: a partial test of the reformulated model of organizational identification', Journal of Organizational Behavior, Vol. 13, No. 2, pp.103-123.

Maroco, J. (2010) Análise de Equações Estruturais: Fundamentos teóricos, software and Aplicações [Structural Equation Analysis: Theoretical, Software and Applications].

Meyer, J., Stanley, D., Herscovitch, L. and Topolnytsky, L. (2002) 'Affective, continuance, and normative commitment to the organization: a meta-analysis of antecedents, correlates, and consequences', Journal of Vocational Behavior, Vol. 61, No. 1, pp.20-52.

Montani, F., Courcy, F. and Vandenberghe, C. (2017) 'Innovating under stress: the role of 
commitment and leader-member exchange', Journal of Business Research, Vol. 77, No. C, pp.1-13.

Peterson, D.K. (2004) 'The relationship between perceptions of corporate citizenship and organizational commitment', Business and Society, Vol. 43, No. 3, pp.296-319.

Podsakoff, P. and Organ, D. (1986) 'Self-reports in organizational research: problems and prospects', Journal of Management, Vol. 12, No. 4, pp.531-544.

Podsakoff, P., MacKenzie, S., Lee, J. and Podsakoff, N. (2003) 'Common method biases in behavioral research: a critical review of the literature and recommended remedies', Journal of Applied Psychology, Vol. 88, No. 5, pp.879-903.

Porter, L., Steers, R., Mowday, R and Boulian, P. (1974) 'Organizational commitment, job satisfaction, and turnover among psychiatric technicians', Journal of Applied Psychology, Vol. 59, No. 5, pp.603-609.

Pundt, A. (2015) 'The relationship between humorous leadership and innovative behavior', Journal of Managerial Psychology, Vol. 30, No. 8, pp.878-893.

Ramamoorthy, N., Flood, P., Slattery, T. and Sardessai, R. (2005) 'Determinants of innovative work behaviour: development and test of an integrated model', Creativity and Innovation Management, Vol. 14, No. 2, pp.142-150.

Rego, A., Cunha, M. and Souto, S. (2007) 'Workplace spirituality, commitment and performance: an empirical study', Management Research, Vol. 5, No. 3, pp.163-183.

Rego, A., Leal, S., Cunha, M., Faria, J. and Pinho, C. (2010) 'How the perceptions of five dimensions of corporate citizenship and their inter-inconsistencies predict affective commitment', Journal of Business Ethics, Vol. 94, No. 1, pp.107-127.

Rego, A., Ribeiro, N., Cunha, M. and Jesuino, J. (2011) 'How happiness mediates the organizational virtuousness and affective commitment relationship', Journal of Business Research, Vol. 64, No. 5, pp.524-532.

Rexhepi, G., Kurtishi, S. and Bexhetic, G. (2013) 'Corporate social responsibility (CSR) and innovation - the drivers of business growth?', Procedia - Social and Behavioral Sciences, Vol. 75, No. 3, pp.532-541.

Robinson, S. and Rousseau, D. (1994) 'Violating the psychological contract: not the exception but the norm', Journal of Organizational Behavior, Vol. 15, No. 3, pp.245-259.

Rodrigo, P. and Arenas, D. (2008) 'Do employees care about CSR programs? A typology of employees according to their attitudes', Journal of Business Ethics, Vol. 83, No. 2, pp.265-283.

Russell, J. (2008) 'Promoting subjective well-being at work', Journal of Career Assessment, Vol. 16, No. 1, pp.117-131.

Spagnoli, P., Caetano, A. and Silva, A. (2012) 'Psychometric properties of a Portuguese version of the subjective happiness scale', Social Indicators Research, Vol. 105, No. 1, pp.137-143.

Tekleab, A. and Chiaburu, D. (2011) 'Social exchange: empirical examination of form and focus', Journal of Business Research, Vol. 64, No. 5, pp.460-466.

Turker, D. (2009a) 'How corporate social responsibility influences organizational commitment', Journal of Business Ethics, Vol. 89, No. 2, pp.189-204.

Impact of CSR perceptions on workers' innovative behaviour 173

Turker, D. (2009b) 'Measuring corporate social responsibility: a scale development study', Journal of Business Ethics, Vol. 85, No. 4, pp.411-427. 
Wenhua, W. (2011) 'Empirical research on knowledge employees' organizational commitment and innovative behavior in high-tech enterprises', International Conference on E-Business and E-Government, pp.1-4.

West, M. and Altink, W. (1996) 'Innovation at work: Individual, group, organizational, and socio-historical perspectives', European Journal of Work and Organizational Psychology, Vol. 5, No. 1, pp.3-11.

West, M. and Farr, J. (1989) 'Innovation at work: psychological perspectives', Social Behavior, Vol. 4, No. 1, pp.15-30.

Wong, Y, Ngo, H. and Wong (2003) 'Antecedents and outcomes of employees' trust in Chinese joint ventures', Asia Pacific Journal of Management, Vol. 20, No. 4, pp.481-499.

Xerri, M. (2013) 'Workplace relationships and the innovative behaviour of nursing employees: a social exchange perspective', Asia Pacific Journal of Human Resources, Vol. 51, No. 1, pp.103-123.

Xerri, M. and Brunetto, Y. (2013) 'Fostering innovative behaviour: the importance of employee commitment and organisational citizenship behaviour', The International Journal of Human Resource Management, Vol. 24, No. 16, pp.3163-3177.

Zapata, C., Olsen, J. and Martins, L. (2013) 'Social exchange from the supervisor's perspective: employee trustworthiness as a predictor of interpersonal and informational justice', Organizational behavior and human decision processes, vol. 121, no. 1, pp.1-12 